\title{
Intertrial inhibition of focused attention in pop-out search
}

\author{
Alejandro Lleras \\ University of Illinois at Urbana-Champaign, Urbana, Illinois \\ JUN-ICHIRO KAWAHARA \\ National Institute of Advanced Industrial Science and Technology, Tsukuba, Japan \\ XIAOANG IRENe WaN \\ University of Illinois at Urbana-Champaign, Urbana, Illinois
}

AND

Atsunori ARiga

University of Tokyo, Tokyo, Japan

\begin{abstract}
When a visual search for a color oddball is performed, responses to target-present trials are affected by the color of items in immediately preceding target-absent trials, a phenomenon known as the distractor-previewing effect (DPE). Specifically, the color of the items in the target-absent trial suppresses responses to a target of that color in the subsequent trial, even though participants report a target feature uncorrelated with color. We believe that this suppression reflects a transient inhibitory effect on focused attention that biases attention away from items that are of the same color as the items in the target-absent trial. Experiments 1-3 show that the DPE is present only in tasks that require focused attention. Experiments 4A and 4B show that the DPE persists even when target-absent displays are masked. Last, Experiment 5 shows that the DPE emerges as early as within the first $100 \mathrm{msec}$ of a target-present trial and is fully in place by the 250 -msec mark.
\end{abstract}

It is generally agreed upon that two different types of information guide the deployment of visual attention during a search task (LaBerge \& Brown, 1989; Wolfe, Cave, \& Franzel, 1989). One type, known as top-down information, refers to an observer's prior knowledge of the target's visual characteristics (e.g., color and shape) as well as of more general information about the task (see, e.g., Downing, 2000; Folk, Leber, \& Egeth, 2002; Lu \& Itti, 2005; Saenz, Buracas, \& Boynton, 2003; Watanabe et al., 1998). In other words, knowing what the target looks like and where it is usually found helps us direct our attention to locations in the world that are likely to contain it. In addition to these knowledge-based influences on visual attention, there are also stimulus-based influences on visual attention, referred to as bottom-up influences. Bottom-up guidance of attention is generally discussed in terms of differences in the salience of stimuli-more salient stimuli are more likely to draw attention to themselves than are less salient stimuli (see, e.g., Itti \& Koch, 2000; Wolfe, 1994).

The most dramatic demonstrations of bottom-up guidance of attention are generally obtained with so-called "pop-out" visual search displays. In these displays, one item differs uniquely from all of the other items along one feature dimension. For example, a display may contain many green items of various shapes and one red item of any given shape. In such cases, our visual attention seems to drift automatically toward the uniquely colored item (here the red item), regardless of our intentions and of the red item's similarity in shape to the green items in the display. Behaviorally, this tendency to focus attention on the unique item is reflected by the fact that, in most popout visual search experiments, the number of distractors in the display does not affect the time it takes participants to find and identify the target. Such empirical findings have been taken as evidence that simple visual features are extracted from the display in a parallel manner, and thus the presence of a feature singleton can be calculated preattentively and can in turn affect the deployment of attention (Itti \& Koch, 2000; Treisman \& Gelade, 1980; Treisman $\&$ Souther, 1985; Wolfe, 1994).

Although pop-out visual search appears to be driven simply by information contained in the stimulus display presented to observers, recent studies have shown that observers' experiences obtained in immediately preceding trials affect their search performance. In particular, Maljkovic and Nakayama (1994, 1996, 2000) have recently focused their investigations on intertrial effects in pop-out searches. Interestingly, they have found that pop-

A. Lleras, alleras@uiuc.edu 
out visual searches can be speeded up by repeating from trial to trial the same pop-out segmentation. For example, if on trial $n$ participants are to identify a green item among red items (a typical pop-out search), they will do so faster if on trial $n-1$, the same color segmentation was present in the display (i.e., a green target among red distractors) than if a different (e.g., orange among ocher) or opposite (red among green) segmentation was used.

Maljkovic and Nakayama $(1994,1996,2000)$ termed this sequential benefit priming of pop-out and interpreted it as an attentional effect. In brief, Maljkovic and Nakayama proposed that when a pop-out target is identified, a short-term memory trace is formed that links focused attention to the pop-out feature of the target. This memory trace, in turn, affects future deployments of focused attention, biasing attention toward items that share the repeated target feature. Further, this bias seems to be sensitive to the specific figure-ground segmentation encountered in the initial presentation of the target, in that repetitions of the same target-distractor set lead to larger biases than when the target color is repeated but the distractor color is not. For example, going from a red target among blue distractors on trial $n$ to a red target among green distractors on trial $n+1$ produces a smaller bias than when both the target and the distractor color are repeated (see Goolsby \& Suzuki, 2001b).

Last, priming of pop-out can also be generated in the absence of a pop-out target on trial $n$, as long as the attended figure-ground segmentation is repeated. For instance, imagine a trial with a display of six stimuli, three red and three green. If participants are directed to attend to the red items, and on the subsequent trial a red pop-out target appears within a set of green distractors, a positive bias to attend to the red target is observed in comparison with a trial in which the target is a green pop-out item among a set of red distractors (Goolsby, Grabowecky, \& Suzuki, 2005). In other words, priming of pop-out seems to reflect a positive attentional bias toward a previously attended color when this color is repeatedly presented in the context of the same distractor color.

\section{The Distractor-Previewing Effect}

More recent studies have documented a related intertrial effect that occurs in the absence of a pop-out target. Goolsby and Suzuki (2001a; see also Goolsby et al., 2005) and Ariga and Kawahara (2004) used a modified version of Maljkovic and Nakayama's (1994) methodology in which both target-present and target-absent trials were intermixed. Target-present trials consisted of conventional pop-out search displays - one color-oddball item (the popout target) among two items of a second color. Ariga and Kawahara then added target-absent trials, which consisted of displays containing three same-colored items (i.e., no color-oddball item popped out). In target-present trials, participants were asked to quickly identify the shape of the color-oddball item, whereas in target-absent trials, participants were asked to withhold any responses. Both studies reported a strong intertrial effect: Viewing a target-absent display influenced response times (RTs) to a subsequent target-present display. Specifically, when participants completed a target-present trial in which the target color was the same as that of the items passively viewed in the immediately preceding target-absent trial, their RTs were about 50-100 msec slower than when the distractors in the target-present trial were of the previewed color (and the target was of a nonpreviewed color). Goolsby et al. referred to this intertrial color-contingency effect as the color salience aftereffect, whereas Ariga and Kawahara termed it the distractor-previewing effect (DPE), in reference to the behavioral benefit observed when distractors in target-present trials were of the same color as the passively viewed items in the preceding target-absent trial (see Figure 1 for an illustration). Henceforth, we will use the term DPE to refer to this effect, since it is less theoretically loaded.

Three things are notable about this effect. First, in spite of its surface similarity to the priming of pop-out phenomenon studied by Maljkovic and Nakayama (1994, 1996, 2000), Ariga and Kawahara (2004) showed a dissociation between the DPE and the priming of pop-out phenomenon. In several experiments that used faces and motion as stimuli, Ariga and Kawahara observed a DPE on target-present trials that followed target-absent trials, but no priming of pop-out was obtained on target-present trials that followed other target-present trials (target-present and target-absent trials were intermixed). Similarly, Goolsby et al. (2005), using the same color stimuli used in the present study, also showed a dissociation between these two effects by showing that priming of pop-out was due to attention-based color segmentation (which occurs when there is no pop-out item on the preceding trial but the attended/ignored color segmentation is repeated between trials), whereas the DPE was due to processing of uniformly colored items. Thus, the DPE can take place in the absence of priming of pop-out.

The second notable thing about the DPE is that it is also different from the phenomenon of negative priming (Tipper, 1985). Negative priming refers to the observation that responses to previously ignored stimuli are typically slower than responses to previously attended or nonpreviewed stimuli. However, previous studies on negative priming have shown that this intertrial repetition effect occurs only when the to-be-ignored stimuli are presented along with the to-be-attended stimuli (Lowe, 1979; Milliken, Joordens, Merikle, \& Seiffert, 1998; Moore, 1994; Tipper \& Cranston, 1985). In other words, selective attention is required for negative priming to take place. In contrast, previous studies (Ariga \& Kawahara, 2004; Ariga, Lleras, \& Kawahara, 2004; Goolsby et al., 2005) have shown that selective attention is not required for the DPE to occur. For example, Ariga et al. showed that a DPE could be observed even when the target-present display contained only one item.

The third and final notable thing about the DPE is that it seems to generalize to stimuli that are more complex than the stimuli used in previous priming of pop-out studies. Ariga and Kawahara (2004) obtained a DPE when the search stimuli were faces as well as when they were shapes defined by moving dots. Further, and even more impressive, a colorbased DPE was observed when the target-present displays contained colored diamond-shaped stimuli and the preview displays (i.e., the target-absent trials) contained words that 

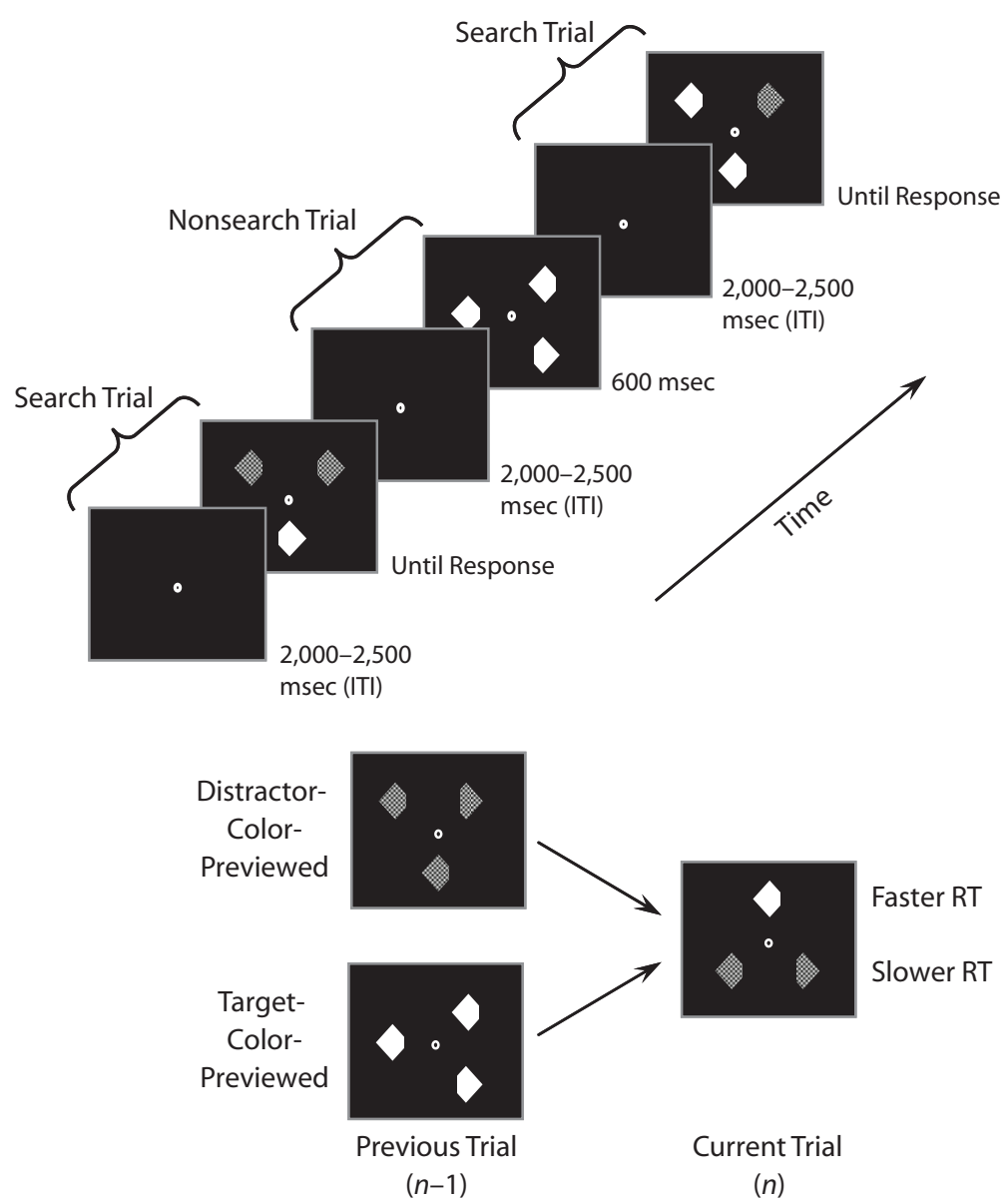

Figure 1. Schematic of the displays and trial sequence. Target-color-previewed trials are those in which the target in a target-present display is the same color as the items in the immediately preceding target-absent display. Distractor-color-previewed trials are those in which the distractors in a target-present display are the same color as the items in the immediately preceding target-absent display.

spelled out the color of either the distractors or the target in the following target-present trial.

To sum up, the DPE can be characterized as a tendency to inhibit the processing of or response to items that share the color of recently (and passively) viewed items. The question at hand, therefore, is: What is inhibited in the DPE? Goolsby et al. (2005) argued that the DPE reflects a type of perceptual suppression akin to a perceptual aftereffect; this is why they referred to the DPE as the colorsalience aftereffect. The data from Ariga and Kawahara (2004), however, tell us that the DPE might not necessarily be confined to the perception of color (since an analogous DPE was observed with faces and moving dots as stimuli) and, furthermore, that the nature of the DPE seems to be different from that of a perceptual aftereffect. Here, we propose that the DPE is an attentional phenomenon, in that it affects the mechanism of attention itself rather than the representations on which attention works (as proposed by Goolsby et al., 2005). In other words, whereas Goolsby et al.'s theory proposes that the effect itself has a clear preattentive locus (the salience of a previewed color is decreased, and as a result, this color is less likely to attract attention), we claim that the DPE reflects a change in the attentional allocation mechanism itself, which means that the visual representations of the items in the search display are not themselves altered in this phenomenon. In all fairness, Goolsby et al. did not explicitly discuss a mechanism by which the salience aftereffect might occur. That being said, for our purposes and in accordance with our reading of Goolsby et al.'s article, we tested a specific instantiation of their theory: that the effect occurs at a preattentive level and involves the modulation (or relative suppression) of the salience of the previewed color. ${ }^{1} \mathrm{We}$ refer to this theory as the preattentive theory of the DPE. We will return to the issue of the mechanisms responsible for the DPE in the General Discussion.

\section{Aim of the Present Study}

The goal of this article is to provide evidence that the DPE reflects inhibition of focused attention. In a typical 
DPE experiment, participants are asked to (1) search for a color oddball and (2) focus their attention on the oddball item to (3) report a second feature of this item (not the pop-out feature). Participants try to complete this task and to optimize their performance on each trial. When the first step (the search for the oddball) is not successful at producing an output for the second step (the selection), the search must be halted. We propose that aborting the search in this way creates a bias against the feature that led to the search's failure. In other words, if searching through a display of red items was halted, a bias to search away from red is created - as if red were deemed a failed feature because it did not lead to the successful completion of the task for that trial.

This adaptive bias is then reflected in subsequent targetpresent trials: If on a subsequent target-present trial, red items are present, a bias to search away from red would (1) produce faster RTs when the target is nonred and the distractors are red and (2) produce slower RTs when the target is red and the distractors are nonred. This attentional bias to search away from a specific color (the failed or previewed color) is therefore a memory trace that acts on the attentional system but not on the visual representations of the search items themselves. We view this phenomenon as analogous to the inhibition of return (IOR) phenomenon (Posner \& Cohen, 1984) that is observed in the domain of spatial attention: When spatial attention is focused at a given location and a target fails to appear at that location, that location is designated as a failed location and a bias to search away from that location ensues (see, e.g., Klein, 2000; Klein \& MacInnes, 1999; McCarley, Wang, Kramer, Irwin, \& Peterson, 2003; Peterson, Kramer, Wang, Irwin, \& McCarley, 2001; Thomas et al., 2006).

Note, too, that this theory is not entirely unlike the initial theory put forward by Maljkovic and Nakayama (1994) to account for priming of pop-out; to put it simply, our theory of the DPE represents the flip side of theirs: Whereas Maljkovic and Nakayama (1994) argued that priming of pop-out reflected a positive bias to focus attention toward the feature that recently led to the successful completion of the discrimination task, here we argue that a DPE reflects a negative bias not to focus attention on the feature that recently led to the failed attempt to complete the discrimination task.

The logic of our study follows that of Bravo and Nakayama's (1992) study on pop-out visual search, in which they proposed a critical distinction between target-detection and target-discrimination tasks in the context of pop-out searches. In target-detection tasks, since the target pops out, the task can be completed without the use of focused attention. In contrast, target-discrimination tasks require focusing attention on the target in order to identify the tobe-reported feature (from here on, we will refer to this feature as the response-defining feature of the target). In other words, in a pop-out visual search, participants can readily (and in parallel) detect the presence of the target, which suffices for arriving at a response in a target-detection task. Similarly, participants can also detect in parallel the absence of the target. Note that in this case, both detecting the presence and detecting the absence of a target represent successful completion of the participants' task. In other words, nothing is left undone at the end of a target-absent trial; there is no failure. As a result, we predict a DPE will never be observed in a target-detection task.

In contrast, in a target-discrimination task, participants need to detect the presence of the target and to focus their attention on the pop-out item in order to identify the response-defining feature of the target. As a result, aborting the search task on target-absent trials without having found a target to focus on can be characterized as a failure in that the readiness of the visual system to focus attention and report a feature of the target is not utilized. As a result, we predict that a DPE will always be observed in target-discrimination tasks.

Our prediction that the DPE will be highly dependent on the task assigned to the observers of the visual display stands in contrast to the preattentive theory of the DPE. This theory proposes that the color salience of items viewed during target-absent trials reduces the salience of that previewed color on the subsequent target-present trial. Notice that this reduction in salience ought to happen regardless of the attentional requirements of the search task itself. The question then arises: Does the preattentive theory of the DPE predict a DPE with a target-detection task? To answer this question, one can appeal to theories of visual search regarding how salience affects RTs in target-detection experiments. Computational theories of visual search such as those of Wolfe (1994) and Itti and Koch (2000) posit that the time it takes for a stimulus to draw attention to itself critically depends on its salience vector. The details regarding how salience is calculated depend on individual models, but the raison d'être of the salience map (in which the salience of all items in the display is represented) is precisely to determine which items ought to be attended and the processing priority of all items in the display. Importantly, the determination of an item's salience depends on its similarity to neighboring items. As a result, when items are similar to each other, the models require more iterations to select the one item with the highest salience. When items are very different from each other, fewer iterations are required to determine the item with the highest salience. Importantly, these salience computations are done preattentively. Therefore, whether the task is target detection or target discrimination, differences in salience must lead to differences in overall RTs (see Navalpakkam \& Itti, 2007, for a recent article reporting these very sets of predictions using the Itti \& Koch, 2000, model of visual search).

In other words, even in the context of a pop-out search task, the ability of an item to pop out from the display will depend on its salience, with highly salient items popping out more readily than less salient items (see Navalpakkam \& Itti, 2007, for a computational demonstration of this effect and Wan \& Lleras, 2007, for direct empirical evidence supporting this claim). In sum, if we apply current theories of visual search to the DPE, and we assume that the DPE reflects a modulation of a color's salience, such modulation must have an effect on both target-detection and target-discrimination tasks.

To summarize, we used Bravo and Nakayama's (1992) logic to investigate whether there is a link between the 
DPE and the attentional constraints of the search task. Specifically, if the DPE is a focused-attention phenomenon, then it ought to be present in tasks that require focused attention (i.e., target-discrimination tasks) and absent in tasks that do not require focused attention (i.e., targetdetection tasks). In contrast, if the DPE is a preattentive phenomenon that represents the suppressed salience of repeated features between trials (Goolsby et al., 2005), the DPE ought to be present regardless of the experimental task (as predicted by current theories of visual search). This follows since in both target-detection and targetdiscrimination tasks, the relative salience of the target affects the detectability of the target (i.e., how quickly a target can be detected), which occurs prior to the focusing of attention on the target.

To test our theory that the DPE reflects inhibition of focused attention, we conducted three experiments. In the first, a between-participants experiment, participants completed identical experiments except that half of the participants were asked to report the presence or absence of an oddball target (a target-detection task), and the other half reported a second feature of the oddball target (a target-discrimination task). To foretell, a DPE was found in the target-discrimination task but not in the target-detection task. Experiments 2 and 3 show that the presence or absence of the DPE across these two tasks was not contingent upon responses (or the lack thereof) to preview displays in these tasks. Last, we present two additional experiments whose results provide converging evidence for the inhibition of focused attention account of the DPE. Experiment 4 shows that the DPE is observed even when dichromatic mask stimuli are used between the target-absent and target-present trials (to dispel doubts regarding color adaptation aftereffects). Finally, Experiment 5 examined the time course of the DPE to show how early in a trial the effect arises.

\section{EXPERIMENT 1}

In this experiment, we examined whether a DPE was obtained in a target-detection task when focused attention to the target was not required to complete the task. For comparison, a second group of participants completed a target-discrimination task using the same displays and timings. To preview, the DPE was not observed in the target-detection task, but it was observed in the targetdiscrimination task.

\section{Method}

Participants. Thirty students from the University of Illinois participated in this experiment. They either were paid $\$ 8$ or received credit to fulfill an introductory psychology class requirement. All participants reported normal or corrected-to-normal visual acuity and normal color vision.

Apparatus and Stimuli. In the present and the following experiments, stimuli were presented at a resolution of $1,024 \times 768$ pixels, in 32-bit color, on a 17-in. Dell monitor with a refresh rate of $85 \mathrm{~Hz}$. A Dell Pentium IV $3.40 \mathrm{GHz}$ computer used MATLAB and the Psychophysics Toolbox (Brainard, 1997; Pelli, 1997) to control the experiments. Responses were gathered with a standard keyboard. Displays consisted of three diamond shapes, each subtending $1.3^{\circ} \times$ $1.3^{\circ}$ in visual angle. The diamonds were each missing either the right or left corner (a $0.22^{\circ}$ chip). They were presented in one of 12 possible locations on an approximate imaginary isoacuity ellipse (Virsu \& Rovamo, 1979) with a vertical axis of $8.2^{\circ}$ and a horizontal axis of $10.1^{\circ}$, with the constraint that the diamonds were equally distributed along the ellipse. The diamonds could be either red or green. The participants viewed the displays in a dimly illuminated room, at a distance of approximately $60 \mathrm{~cm}$.

Task and Design. A between-participants design was used. Half of the participants completed a target - detection task in which they indicated the presence or absence of a color oddball in the display by pressing the right or the left arrow keys, respectively, on the keyboard. Each participant completed 12 blocks of 96 trials each. The remaining participants completed a target-discrimination task in which they indicated the missing corner of the color oddball (right or left) in the display by pressing the right or left arrow keys, respectively, on the keyboard. In trials in which no color oddball was present (target-absent trials), the participants were instructed to withhold their responses. Each participant completed 6 blocks of 160 trials each. The participants were encouraged to respond as quickly as possible while maintaining a high level of accuracy.

For every participant, a sequence of trials was determined to ensure that the color of items in target-absent trials was equally often the color of the target and the color of the distractors in the immediately following target-present trial (target-present trials were always preceded either by a target-absent trial or by another target-present trial). When a target-present display was preceded by a target-absent display, two types of trials were defined: target-previewed trials (in which the current target color was the same as the color of the items in the preceding target-absent trial) and distractor-previewed trials (in which the current distractor color was the same as the color of the items in the preceding target-absent trial). In Ariga and Kawahara's (2004) terms, a DPE is the difference between target-previewed RTs and distractor-previewed RTs. When a target-present display was preceded by a target-present display, two types of trials were defined: search-repeat trials (in which the current target and distractor color assignment was the same as in the preceding target-present trial) and search-reverse trials (in which the current target and distractor color assignment was the reverse of that in the preceding target-present trial). In Maljkovic and Nakayama's (1994) terms, priming of pop-out is the RT difference between search-reverse and search-repeat RTs.

Procedure. Trials began with the presentation of a fixation display with a random duration of 1,500-2,000 msec. The search display was then presented for $1,000 \mathrm{msec}$ or until the participant responded, whichever happened first. In the target-discrimination task, target-absent displays were presented for $600 \mathrm{msec}$. On targetpresent trials, one of the diamonds was of a different color than the other two. On target-absent trials, all three diamonds were of the same color. In all trials, one of the diamonds was missing a different corner than the other two diamonds.

\section{Results}

Target-detection group. The participants' accuracy was very high on target-present trials (mean 99.0\%) and did not change as a function of the previous trial (target preview, distractor preview, search reverse, or search repeat) $[F(3,42)=2.04, p>.05]$. Accuracy was higher overall on target-present trials $(99.0 \%)$ than on targetabsent trials $(96.7 \%)[t(14)=4.17, p<.05]$. A similar analysis of RTs for correct responses on target-present trials revealed no effects of previous trial $[F(3,42)=1.21$, $p>.05]$. In particular, as Figure 2 shows, mean RTs in the target-previewed condition $(563 \mathrm{msec})$ were not significantly slower than those in the distractor-previewed condition $(559 \mathrm{msec})[t(14)<1]$, revealing the absence 
of the DPE. Similarly, there was no priming of pop-out in this experiment: Mean RTs on search-reverse trials $(545 \mathrm{msec})$ were not significantly faster than mean RTs on search-repeat trials $(548 \mathrm{msec})[t(14)<1]$. Finally, RTs were $20 \mathrm{msec}$ slower on target-absent trials than on target-present trials $[t(14)=3.53, p<.05]$.

Target-discrimination group. The participants' accuracy was high on target-present trials $(96.3 \%)$ and did change significantly as a function of preview type $[F(3,42)=3.65, p<.05]$. Interestingly, this main effect was due to somewhat lower accuracy $(95.2 \%)$ in the search-reverse condition. Accuracy did not significantly differ in the other three conditions: search repeat (96.4\%), distractor previewed $(96.7 \%)$, and target previewed $(96.8 \%)[F(3,28)<1]$. In contrast, RTs for correct responses showed strong effects of preview type $[F(3,42)=$ $77.58, p<.05]$. Most importantly, as Figure 2 shows, there was a significant DPE of $73 \mathrm{msec}$, with mean RTs in the target-previewed condition $(735 \mathrm{msec})$ significantly slower than mean RTs in the distractor-previewed condition $(662 \mathrm{msec})[t(14)=11.98, p<.05]$. A significant 42-msec priming of pop-out effect was also obtained, with mean RTs in the search-reverse condition $(741 \mathrm{msec})$ slower than mean RTs in the search-repeat condition $(699 \mathrm{msec})[t(14)=7.71]$.

\section{Discussion}

The results of Experiment 1 show a clear pattern: Whereas a substantial DPE effect was observed with the target-discrimination task, there was no evidence of even a slight intertrial effect with the target-detection task. As mentioned earlier, a crucial difference between the targetdetection and target-discrimination tasks is that the former does not require the focusing of attention on the target, whereas the latter does. However, it would be hasty to conclude that the elimination of the DPE in the targetdetection task was indeed due to this difference, for two important reasons. First, skeptical readers might wonder whether differences in the target salience might in fact lead to differences in detectability in a target-detection task; after all, in a color-oddball detection task, all one needs to know to respond is that there is a color discontinuity in the display, and one might be able to detect this discontinuity regardless of its magnitude.

To answer this concern, we direct readers to computational evidence from Navalpakkam and Itti (2007), who presented modeling results showing that target-distractor discriminability does affect detection times. In addition, we direct readers to another study from our lab (Wan \& Lleras, 2007) in which we directly tested this assumption. In Experiment 1 of that study, we asked participants to complete a series of detection task blocks. Relevant to our present point, participants were asked to detect a coloroddball target in two conditions that were almost identical except that the color salience of the target pop-out was manipulated between conditions. In one block condition, trials contained a highly salient pop-out (search items could be either bright red or bright green); in other blocks, trials contained a less salient pop-out (search items could be either fuchsia or pinkish-orange, two colors that are close in luminance and similar in spectral composition).

Not surprisingly, we found that participants could detect the color oddball in both conditions irrespective of set size (i.e., both conditions produced pop-out searches with 0 -msec/item search slopes). More interestingly, the color oddball in the highly salient condition was detected

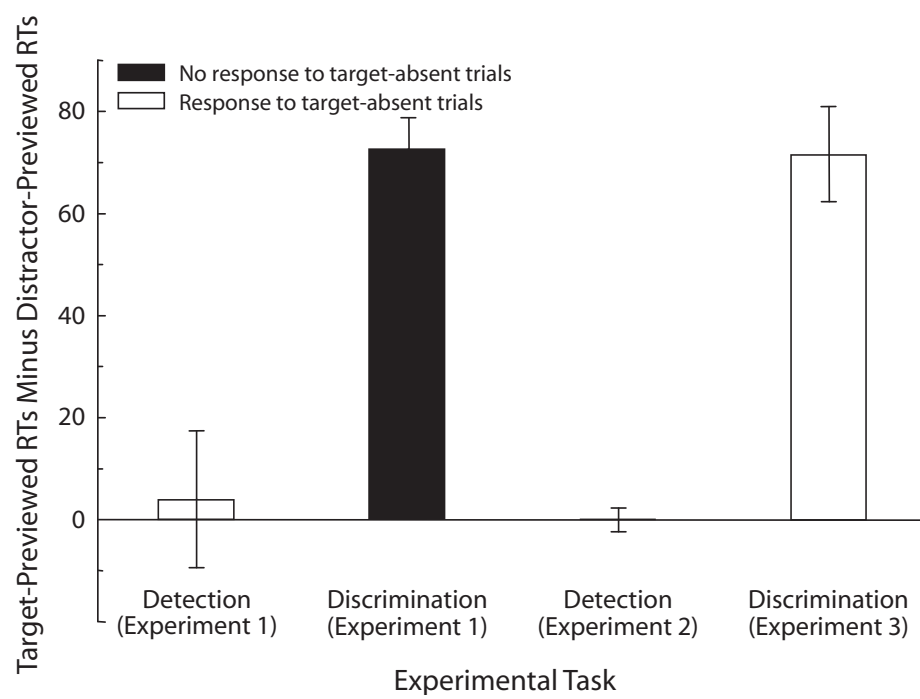

Figure 2. Results of Experiments 1, 2, and 3. The response time (RT) difference between target-previewed and distractor-previewed trials is plotted on the $y$-axis as a function of the experimental task (target detection vs. target discrimination). White bars indicate experiments in which participants were asked to respond to target-absent trials, and black bars indicate experiments in which participants were asked to withhold responses to target-absent trials. 
$133 \mathrm{msec}$ faster (mean RT of $565 \mathrm{msec}$ ) than the color oddball in the less salient condition (mean RT of $698 \mathrm{msec}$ ) $[t(14)=7.33, p<.01]$. It should be noted that all other elements of Wan and Lleras's (2007) Experiment 1 were identical to the experimental conditions of the present Experiment 1: The same eccentricity was used, the red and green colors were the same, and the shape of the items (diamonds with missing corners) was also the same. In sum, we have both theoretical and empirical evidence that differences in target salience do result in differences in detectability, even in a pop-out search. Therefore, if the DPE reflected a difference in the color salience of the target (modulated by the type of previous target-absent trial), that modulation of target salience should have been observed in the target-detection task, and yet it wasn't.

That being said, before we can confidently conclude that focused attention is a requirement for the DPE, one other important difference between these two tasks ought to be ruled out. The other crucial difference between the tasks is that on the target-detection task, participants made a response to the target-absent displays, whereas they withheld a response to those displays in the targetdiscrimination task. Thus, it is entirely possible that (1) the absence of the DPE in the target-detection task was somehow related to the fact that participants responded to the target-absent displays or (2) the presence of the DPE in the target-discrimination task was somehow related to the withholding of responses to target-absent displays. Experiments 2 and 3 were designed to address these possibilities in turn. Last, it is worth noting that we did not have a baseline RT measure in this experiment. The color of the items on a target-absent display was always present in the subsequent target-present display, as either the color of the target or the color of the distractors. In Experiment 3, we included a baseline experimental condition (the nopreviewed-color condition) to assess the relative costs and benefits embedded in our DPE measure.

\section{EXPERIMENT 2}

Experiment 2 was a replication of the target-detection condition of Experiment 1 except that participants were asked to respond only to the presence of a target (and thus to refrain from responding to target-absent displays). If the DPE is somehow related to the absence of a response in target-absent trials, a DPE ought to be observed in this experiment even though participants were not required to focus their attention on the target to complete the task.

\section{Method}

Participants. Fifteen undergraduate students from the University of Illinois participated in this experiment, either in exchange for extra credit in an introductory psychology course or for payment of $\$ 8$ for a 1-h session. All participants reported normal or correctedto-normal visual acuity and normal color vision.

Task, Design, and Procedure. The method of Experiment 2 was in every way identical to that of the target-detection task of Experiment 1 except for the following: Participants were asked to withhold their responses on target-absent trials. On target-present trials, participants were instructed to respond by pressing the down-arrow key. Each participant completed five blocks of 160 trials each.

\section{Results}

Overall, the participants' accuracy on this task was high $($ mean $=94.7 \%)$. Accuracy on target-present trials was overall lower when it followed another target-present trial (94.6\%) than when it followed a target-absent trial (96.3\%) $[t(14)=2.86, p<.05]$; however, as in Experiment 1 , accuracy within these cases was unaffected by preview type. Accuracy on target-previewed trials $(96.0 \%)$ was not significantly different from accuracy on distractorpreviewed trials $(96.6 \%)[t(14)<1]$, and accuracy on search-reverse trials $(94.5 \%)$ was no different from that on search-repeat trials $(94.6 \%)[t(14)<1]$. Overall, the participants committed few false alarms $(6.4 \%)$. In sum, no color-mediated intertrial effects on accuracy were observed in this experiment.

Similarly, an analysis of RTs for target-present trials revealed no effects of previous trial $[F(3,42)<1]$. As Figure 2 shows, mean RTs in the target-previewed condition $(404 \mathrm{msec})$ did not differ from those in the distractorpreviewed condition $(404 \mathrm{msec})[t(14)<1]$, revealing the absence of the DPE. Similarly, there was no priming of pop-out in this experiment: RTs on search-reverse trials $(400 \mathrm{msec})$ were not significantly faster than RTs on search-repeat trials $(402 \mathrm{msec})[t(14)<1]$.

\section{Discussion}

The results of Experiment 2 strongly suggest that the lack of a DPE in the target-detection task in Experiment 1 was not due to the fact that participants were responding to target-absent displays (rather than withholding their responses, as in the target-discrimination task). Instead, the results of Experiment 2 are still in line with our hypothesis that focused attention is necessary to obtain a DPE. This follows, given that in Experiment 2, participants could once again perform the task without focusing attention on the color-oddball target, and once again, no DPE was found. Taken together, the results of Experiments 1 and 2 suggest that responding (or not) to target-absent displays plays no role in the DPE, at least in the context of a targetdetection task. However, it is still possible that the DPE is somehow caused by the lack of a response to targetabsent displays when that null response occurs within the context of a target-discrimination task. Experiment 3 was designed to examine this possibility.

\section{EXPERIMENT 3}

Experiment 3 followed closely the target-discrimination condition of Experiment 1, except that in addition to identifying targets on target-present trials, one group of participants (the go group) were asked to respond to the absence of a target on target-absent trials, and the other group of participants (the no-go group) were asked not to respond. If the DPE observed in Experiment 1 was somehow related to the absence of a response in target-absent trials (in the context of a target-discrimination task), then the DPE ought to be eliminated when participants produce responses to targetabsent displays. If, however, the act of producing (or withholding) a response in target-absent trials is unrelated to the DPE, we ought to once again observe a normal DPE. 
In addition to the go/no-go manipulation, we included in this experiment a neither-color-previewed condition by adding a third possible stimulus color (white) to our design. This new condition allowed us to evaluate the baseline RT in our experiments. The neither-color-previewed condition occurred when neither the color of the target nor of the distractors in the current target-present trial had been previewed in the preceding target-absent trial. If the DPE reflects an inhibitory effect preventing or delaying focused attention to items sharing the color previewed in the preceding target-absent trial, we might observe both a cost in the target-previewed condition and a relative benefit in the distractor-previewed condition as compared with the neither-color-previewed condition, since in the latter condition attention is biased away from focusing on color-previewed items.

\section{Method}

Participants. Twenty undergraduate students from the University of British Columbia participated in this experiment in exchange for extra credit in an introductory psychology course. All participants reported normal or corrected-to-normal visual acuity and normal color vision.

Procedure. The procedure of Experiment 3 was similar to that of the target-discrimination task of Experiment 1 except for the following: The 10 participants in the go group were asked to respond on target-absent trials, whereas the 10 participants in the no-go group withheld responses on those trials (as in Experiment 1). On targetabsent trials, participants in the go group were instructed to press both response keys (the left and the right arrow keys) as soon as they detected the absence of a target in the display. Furthermore, the design of the experiment was changed to include three possible colors (red, green, and white). The sequence of trials was generated to include the following three pairs of target-absent followed by targetpresent color combinations: In the target-previewed condition, the target-absent color on trial $n-1$ was the same as the target color on trial $n$, with equal likelihood that the color of the distractors on trial $n$ would be either of the two colors not used on trial $n-1$; in the distractor-previewed condition, the target-absent color on trial $n-1$ was the same as the distractor color on trial $n$, with equal likelihood that the color of the target on trial $n$ would be one of the two colors that were not used on trial $n-1$; and finally, in the neither-previewed condition, the target-absent color on trial $n-1$ was the same as that not used on target-present trial $n$, with equal likelihood that either of the unused colors would be the target/distractor color. Overall, participants completed 96 trials of each condition distributed over eight blocks of trials.

Because of the increased number of possible pairs, and to keep the experimental session within $1 \mathrm{~h}$, we also constrained the sequence of trials so that it did not include two target-present trials in a row. This design constraint made it impossible to evaluate priming of pop-out effects in this experiment, but in our view, this was an acceptable change to our procedure since our investigation focused primarily on the DPE. Last, the experimental sequence of trials for each participant included $20 \%$ of target-absent followed by target-absent trials.

\section{Results}

Accuracy was similarly high for both groups, with participants in the no-go group averaging $96.7 \%$ correct responses, and participants in the go group, $96.6 \%$ correct. Accuracy patterns were analyzed with response group as a between-subjects variable and preview type as a within-subjects variable. The between-subjects factor response group was not significant $[F(1,18)<1]$. The preview type factor showed a pattern of performance simi- lar to that observed on prior experiments, with distractorpreviewed trials having the highest accuracy (97.2\%), neither-previewed trials $(96.9 \%)$ in the middle, and targetpreviewed trials the lowest $(95.9 \%)[F(2,36)=3.64, p<$ $.05]$. Finally, the interaction of preview type $\times$ response group was not significant $[F(2,36)=2.45, p>.05]$.

Next, we analyzed the RT patterns with response group as a between-subjects variable and preview type as a within-subjects variable. The data resulting from this analysis are shown in Figure 3. The between-groups factor response group was not significant: mean RTs in the no-go and go groups were $694 \mathrm{msec}$ and $702 \mathrm{msec}$, respectively $[F(1,18)<1]$. Both groups showed the same pattern of performance, with the fastest RTs on distractor-previewed trials (647 and $668 \mathrm{msec}$ for the no-go and go groups, respectively), intermediate RTs on neither-previewed trials (687 and $698 \mathrm{msec}$ for the no-go and go groups, respectively), and the slowest RTs on target-previewed trials (747 and $739 \mathrm{msec}$ for no-go and go groups, respectively). Accordingly, the effect of preview type was significant $[F(2,36)=101.68, p<.05]$. The preview type $\times$ response group interaction was not significant $[F(2,36)=$ $2.86, p>.05]$. Finally, planned pairwise comparisons confirmed that RTs on the neither-previewed trials were significantly slower than RTs on distractor-previewed trials [mean difference of $35 \mathrm{msec} ; t(19)=5.31, p<.05$ ] and significantly faster than on target-previewed trials [mean difference of $50 \mathrm{msec} ; t(19)=8.43, p<.05$ ].

\section{Discussion}

The results from Experiment 3 show that a DPE can be obtained even when participants are asked to respond on target-absent trials within the context of a targetdiscrimination task. Moreover, the lack of an interaction between preview type and response group suggests that the DPEs for the go and no-go groups were indeed very comparable. In sum, the results of this experiment are very much in line with those of Experiments 1 and 2: Once again, a substantial DPE was observed when a targetdiscrimination task was used, and furthermore, whether or not participants responded to target-absent trials had no effect on the presence of a DPE (or its absence in Experiment 2). Overall, these results provide strong evidence that the DPE is not related to the withholding of responses on target-absent trials.

With respect to the point that responses (or the lack thereof) to target-absent trials are not required to produce a DPE, we must point out that this is consistent with other results from Goolsby et al. (2005). In two experiments (Experiments 3.3A and 3.3B), Goolsby et al. also asked their participants to produce responses to targetabsent displays, and they also failed to find an effect on the DPE of responses to target-absent displays. However, their manipulations were substantially different from ours in one critical aspect: In both of those experiments, Goolsby et al. asked participants to perform a different task on target-absent trials than on target-present trials. In Experiment 3.3A, participants were instructed to report whether one of the display items briefly changed in size $600 \mathrm{msec}$ after the onset of the target-absent display; in 


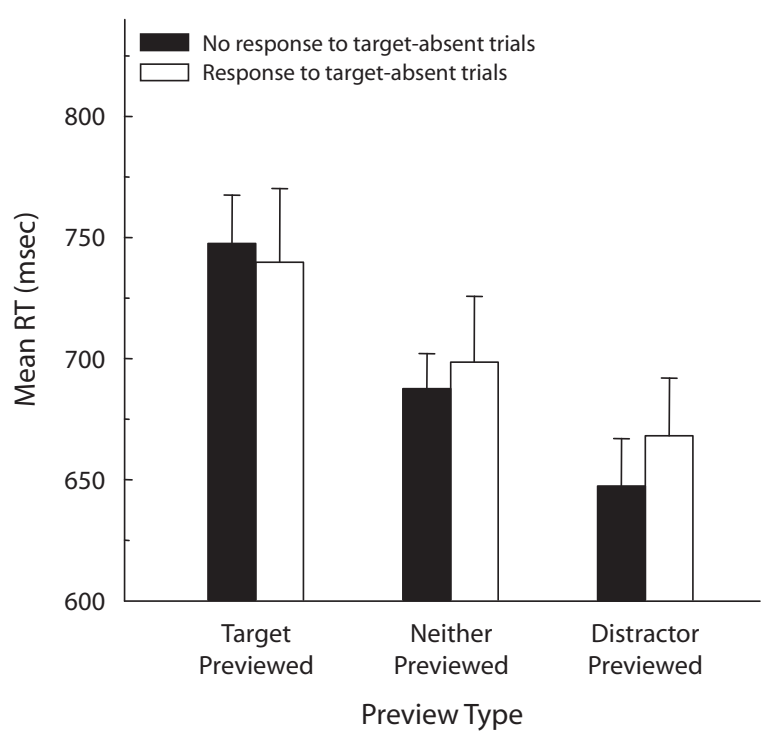

Figure 3. Mean response times (RTs) in Experiment 3 as a function of preview type. White bars represent RTs for participants who responded to target-absent trials, and black bars represent RTs for participants who did not respond to target-absent trials.

Experiment 3.3B, participants were asked to report the missing side of an exogenously cued item in the targetabsent display. It is easy to see that both of those tasks had requirements very different from those of the task that participants typically performed in our target-absent trials (i.e., detect the absence of a color oddball). As a result, participants in the Goolsby et al. experiments were asked to actively maintain two different task sets: one for targetpresent trials and one for (some of the) target-absent trials. That being said, results from the Goolsby et al. experiments and those from our Experiments 2 and 3 are very much in line and really do suggest that the DPE is not due to the absence of a response to target-absent displays. Whether participants respond to the displays to report the absence of a color oddball (as in our Experiments 2 and 3 ) or use the displays to perform a separate perceptual task (as in Goolsby et al.'s, 2005, Experiments 3.3A and 3.3B), their responses do not preempt a DPE from occurring (insofar as the task on target-present displays is a target-discrimination task).

A final point should be noted regarding our results. We found intermediate RTs in the neither-previewed condition, and this result is well in agreement with the findings of Experiment 1.1 of Goolsby et al. (2005). In that experiment, in addition to green and red preview displays, the authors also used an achromatic preview display in which all of the items were white. The RTs on the subsequent target-present trials were fastest in the distractor-previewed condition, slowest in the target-previewed condition, and intermediate in the achromatic-previewed condition. One critical difference, however, between our results and theirs is that Goolsby et al. never used achromatic items in target-present trials, whereas we used all three colors interchangeably as potential colors in both target-absent and target-present displays. Consequently, our results are a generalization of their findings: Achromatic items can produce the same type of preview effect that red and green items can. To be clear, this does not present a direct challenge to the preattentive theory of the DPE: One could posit that the salience of white is reduced following preview, just as the salience of red and green is. That said, this result is one that Goolsby et al. did not test for and that we observed in the present experiment. ${ }^{2}$

Taken together, the results from Experiments 1, 2, and 3 strongly suggest that the presence or absence of a DPE in these experiments must be related to the different attentional profiles of the detection and discrimination tasks, rather than to differences in response requirements among the tasks. As Bravo and Nakayama (1992) argued, focused attention is not necessary to complete the target-detection task, whereas focused attention is needed to complete the target-discrimination task. We propose that it is the task requirement to focus attention on pop-out items that leads the attentional system to be in an inhibitory state following target-absent trials. To be more specific, let us assume that the attentional system has a goal to quickly focus on pop-out items to extract detailed shape information. Consequently, target-absent trials are problematic in that they do not allow for the successful completion of these successive actions (search, focus, and extract): The search aspect of this sequence is in fact aborted without having located a target on which to focus attention. We argue that aborting the search with no positive result leaves a trace in the attentional system that associates failure with the viewed feature (e.g., in a target-absent trial containing all red items, the suppressive trace left in the attentional system would be along the lines of "red items do not [are unlikely to] contain target"). This trace, in turn, ends up affecting the deployment of focused attention in the immediately following trial: Focused attention is slowed down when it has to focus on the previously failed feature (i.e., if the target in the current trial is red) and relatively speeded when it has to focus away from the previously failed feature.

Finally, the results from Experiment 3 can be taken one step further: They suggest that this suppressive state of focused attention also leads to a behavioral benefit when the distractors in the current target-present trial are the same color as the items in the previous target-absent trial. This follows from the observation that, in Experiment 3, RTs were significantly faster in the distractor-previewed condition than in the neither-previewed (baseline) condition. This behavioral benefit likely reflects the reduced competition for focused attention from these previewed distractors. In other words, if the focusing of attention to red items is suppressed, focusing attention to nonred targets is relatively easier when such targets are surrounded by red distractors than when they are surrounded by nonred distractors, because in the former case, there is a built-up inhibition to focus attention on the red distractors (which therefore compete less for attention), whereas in the latter case, the built-up attentional inhibition is neutral with respect to the items currently in view.

We must note that Goolsby et al. (2005) proposed a different account for the DPE, which they had initially 
referred to as the color salience aftereffect. As this name indicates, these authors proposed that the phenomenon reflects an adaptive mechanism that biases attention toward new colors from trial to trial (at least, within the context of pop-out searches). The mechanism behind this effect is akin to a perceptual aftereffect: Viewing a color in a targetabsent display leads to that color's having reduced salience on a subsequent target-present display. The phenomenon is thus not in and of itself an attentional phenomenon (in that it does not directly affect the mechanisms of attention) but is better understood as a preattentive phenomenon that influences the representations on which attention acts.

Let us now address how our present results relate to this preattentive account of the DPE. Although Goolsby et al.'s (2005) methods and ours are very similar, one crucial difference sets the two studies apart: Whereas we investigated the presence/absence of the DPE by changing the experimental task, Goolsby et al., for the most part, documented the presence of the DPE by manipulating factors relating to the target-absent displays (17 experiments) while leaving the target-present displays unchanged. More crucially, they also always used a target-discrimination task. Thus, they never observed the absence of a DPE in a simple target-detection task. As it turns out, a targetdetection task is a critical test of any preattentive theory of the DPE. If, as Goolsby et al. suggested, the DPE is caused by the mere preview of a color in the target-absent trial, the task that participants perform in target-present trials ought not to matter: Whether participants are reporting the presence of the target or its identity, the target's color salience should in both cases be reduced if the color was seen on the previous target-absent trial (Itti \& Koch, 2000; Navalpakkam \& Itti, 2007; Wan \& Lleras, 2007). In other words, the color salience aftereffect account predicts that a DPE ought to be found in both target-detection and target-discrimination cases. As Experiments 1-3 have demonstrated, this is clearly not the case. The DPE was found only in target-discrimination tasks and was entirely absent in target-detection tasks, thus potentially ruling out the color aftereffect account. However, before we confidently concluded against the salience aftereffect account, we sought to test it once more in Experiment 4.

\section{EXPERIMENT 4A}

The preattentive account of the DPE states that viewing same-color items on target-absent trials will reduce the salience of items of that color on the ensuing target-present trial. Although this account cannot easily explain the absence of a DPE when a target-detection task is used, one might argue that the salience of items is calculated/used differently in detection versus discrimination tasks. Thus, to more fairly test the preattentive account, we designed an experiment that preserved the target-discrimination task while manipulating the magnitude of the color aftereffects evoked by the target-absent trials. This was achieved by presenting masking displays after target-absent displays. The masking displays consisted of bicolor diamonds that appeared at the locations of items in the target-absent trials. These masks should decrease the color aftereffect created by the target-absent items. This reasoning is in keeping with recent findings showing that chromatic information can be masked with chromatic masks and further, that chromatic masking reflects interactions at an early, stimulus-level processing stage in which the processing of the mask's wavelength information interferes with the processing of the to-be-masked stimulus's wavelength information (Breitmeyer, Ogmen, \& Chen, 2004; Breitmeyer, Ro, \& Singhal, 2004). In other words, chromatic masking directly affects the salience calculation of the to-be-masked stimulus. If, on the other hand, the masks have no influence on the DPE, then this would provide converging evidence that the DPE is not related to the salience of previously viewed items.

It is also worth noting that Goolsby et al. (2005) found that the duration of the target-absent display significantly affected the DPE, with shorter displays yielding smaller effects than longer displays. In their Experiment 1.3, they found a DPE with target-absent display durations as short as $27 \mathrm{msec}$. However, the overall magnitude of the effect was about $40 \%$ smaller than that of the DPE obtained with the usual $600-\mathrm{msec}$ display duration. Thus, our rationale here was somewhat analogous to theirs: If the DPE is a perceptual phenomenon, a manipulation that reduces the magnitude of the aftereffect (here, the presence of the bicolor mask) ought to reduce the DPE, much as decreasing the duration of the display reduced it in Goolsby et al.'s study.

\section{Method}

Participants. Fifteen undergraduate students from the University of Illinois participated in this experiment for extra credit in an introductory psychology course or for $\$ 8$ for a 1-h session. All participants reported normal or corrected-to-normal visual acuity and normal color vision.

Stimuli. The search display items were identical to those used in the previous experiments. Masking items consisted of diamonds identical in size to those used on search displays but with no missing corner. In addition, each masking diamond was divided into four quadrants (upper right, upper left, lower right, and lower left), each of which was filled with either of the colors used on the search displays (red and green), with the constraint that opposite quadrants were the same color (e.g., upper right and lower left quadrants were green whereas upper left and lower right quadrants were red or vice versa).

Apparatus, Task, Design, and Procedure. Experiment 4 closely followed the procedure used in the target discrimination task of Experiment 1 with the following exception: Each participant completed two different blocks of trials. In the masking block, masking displays were presented after each target-absent trial. These displays consisted of three masking items presented in the locations occupied by the three items on the target-absent display. Masking displays were presented immediately after the target-absent display (0-msec ISI) and appeared for $200 \mathrm{msec}$. In the control block, no masking displays were used. The order of blocks was counterbalanced. Each block consisted of 384 trials, with a brief break halfway through.

\section{Results}

Accuracy on target-present trials was very high for both masked and control trials (mean accuracy $96.5 \%$ and $96.9 \%$, respectively). Accuracy data were submitted to an ANOVA with the factors preview type (distractor and target previewed, as well as search reverse and search repeat) and trial type (masked vs. control). Neither the main effect of masking nor the interaction of masking $\times$ preview 
type was significant (both $F_{\mathrm{S}}<1$ ). Only preview type had a significant effect on accuracy; this effect mimicked the pattern of results from previous experiments: Accuracy was highest in the distractor-previewed (97.4\%) and search repeat $(97.1 \%)$ conditions and lowest in the targetpreviewed $(96.7 \%)$ and search reverse $(95.7 \%)$ conditions $[F(3,42)=3.00, p<.05]$.

The analysis of target-present RTs for correct trials revealed an analogous pattern of results. Most importantly, neither the main effect of masking, nor the interaction of masking $\times$ preview type, was significant (both $F_{\mathrm{S}}<1$ ). Preview type did have a significant effect on RTs, showing both a DPE and a priming of pop-out effect $[F(3,42)=$ $14.40, p<.05]$. Regarding the DPE, RTs were faster in the distractor-previewed condition $(728 \mathrm{msec})$ than in the target-previewed condition $(793 \mathrm{msec})$, with no effect of masking condition (magnitudes of masked and unmasked DPEs were $68 \mathrm{msec}$ and $61 \mathrm{msec}$, respectively — not significantly different from each other $[t(14)<1]$ ). These data are summarized in Figure 4. Regarding priming of pop-out, RTs were faster on search repeat trials $(745 \mathrm{msec})$ and longest on search reverse trials $(821 \mathrm{msec})$.

\section{Discussion}

Experiment 4A tested whether the DPE would be affected by the presence of bicolor masks at the locations of target-absent items. The presence of bicolor masks should have reduced the color aftereffect produced by the viewing of target-absent items. There was no evidence of such an effect. On the contrary, the results suggest that if participants are given adequate time to view the target-absent display (enough to notice the absence of a target), a DPE will occur. This DPE seemed insensitive to the masking of target-absent items. This result provides converging evidence that the DPE is most likely not caused by a color salience aftereffect. The present results are also in line with the inhibition of focused attention account. However, one must be cautious when drawing theoretical conclusions from what is basically a null result. Because of such concerns, we conducted Experiment 4B to further test for the effects of masking on the DPE.

\section{EXPERIMENT 4B}

In Experiment 4B, we further tested the effect of the masking displays on the DPE. Experiment 4B differed from Experiment 4A in two important respects. First, the durations of the target-absent and masking displays were changed. Since the lack of a masking display effect in Experiment 4A may have been due to the short duration $(200 \mathrm{msec})$ of the masking displays with respect to the duration of the target-absent displays $(600 \mathrm{msec})$, we reversed that relationship in Experiment 4B by increasing the duration of the masking displays to $600 \mathrm{msec}$ while reducing the duration of target-absent displays to $100 \mathrm{msec}$. Second, we varied the ISI between the offset of the targetabsent display and the onset of the masking display. This manipulation was aimed at modulating the interaction between the color representations in the target-absent display and those in the masking display.

\section{Method}

The method of Experiment 4B was identical to that of Experiment 4A, except as already noted. The variable ISI was manipulated between groups of 10 participants each. The ISI was measured from the offset of the target-absent display to the onset of the masking display. Three durations were tested: $50 \mathrm{msec}, 250 \mathrm{msec}$, and 1,000 msec. The duration of the target-absent display was reduced to $100 \mathrm{msec}$ and that of the masking display was increased to $600 \mathrm{msec}$. Thirty undergraduate students drawn from the same pool as in Experiment 4A participated.

\section{Results and Discussion}

Our analyses focused on the masking blocks. Overall accuracy was high (98\%). Neither preview type nor the between-subjects variable ISI significantly influenced accuracy in masked blocks (both $F_{\mathrm{S}}<1$ ); nor was the interaction significant $[F(2,27)<1]$. Remarkably, the analysis of the RTs in the masked blocks of Experiment 4B revealed a significant DPE in all three ISI groups, with respective magnitudes of $35 \mathrm{msec}, 30 \mathrm{msec}$, and $24 \mathrm{msec}$ for the 50-msec, 250-msec, and 1,000-msec ISI groups, respectively. Correspondingly, preview type had a significant effect on performance $[F(1,27)=35.47, p<.05]$. More importantly, the between-subjects variable ISI did not significantly impact performance $[F(2,27)=2.00$, $p>.05]$. Last, the interaction between ISI and preview type was not significant $[F(2,27)<1]$. Thus, even though the magnitude of color aftereffects induced by the targetabsent displays should have been widely different when colors were immediately masked (ISI of $50 \mathrm{msec}$ ) versus when they were masked much later (ISI of $1,000 \mathrm{msec}$ ), the DPE did not change in size.

We take the results of Experiment 4B as converging evidence for our attentional account of the DPE. This is

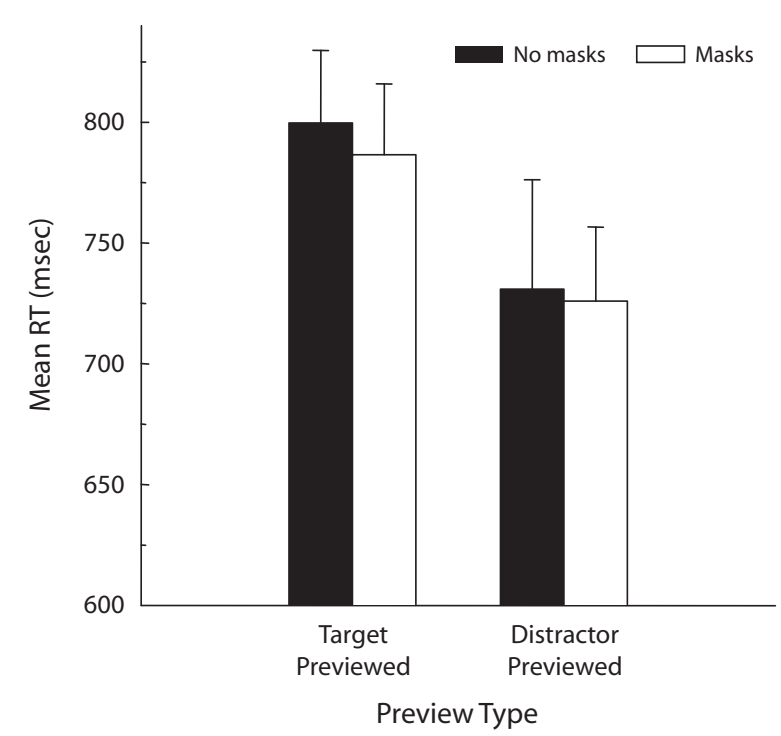

Figure 4. Mean response times (RTs) in Experiment 4A as a function of preview type (target previewed vs. distractor previewed) and mask condition (no mask display following targetabsent displays [black bars] vs. mask display following targetabsent displays [white bars]). 
because in all three masking conditions of Experiment 4B, participants had the same experience with the targetabsent display: During their brief glance at the displays, they were able to notice the absence of a color oddball and thus to associate the absence of a target with the previewed color. In brief, the previously failed feature trace had a chance to be formed and thus to affect the deployment of attention in the subsequent trial. These findings present a challenge to a strict salience aftereffect account of the DPE, since one would expect preview displays with lower salience to produce smaller DPEs (as in Experiment 1.3 of Goolsby et al., 2005). If anything, the magnitude of the DPE in Experiment 4B seemed to decrease as the ISI increased. That being said, it is still possible that our masking manipulation was too weak and did not significantly affect the previewed items' salience. To test for the effectiveness of our masks, we conducted one final control experiment.

In our final control experiment, we asked 12 new participants drawn from the same participant pool to complete a color-oddball detection task. In other words, participants' only task was to indicate whether or not a target was present in the display. Our rationale was that if our masks were effective and did in fact interfere with the salience computation of the items in the display, then detecting the presence of a color-oddball target would be hardest on those trials in which our colored masks maximally interfered with the perceptual processing of the search stimuli. Similarly, it should be easiest to detect the presence or absence of an oddball on those trials in which masks were not presented or were ineffective.

As in Experiment 4B, the duration of the search display was $100 \mathrm{msec}$ and that of the masking display was $600 \mathrm{msec}$. Three different masking conditions were tested by varying the ISI between the search display and the masking display; the three ISIs used were $0 \mathrm{msec}, 50 \mathrm{msec}$, and $250 \mathrm{msec}$. As expected, these search-mask ISI conditions had a significant effect on oddball-detection accu$\operatorname{racy}[F(2,22)=14.28, p<.001]$, with detection accuracy significantly worse at the 0 -msec ISI (84\%) and improving with increasing ISI durations, to $92 \%$ at the $50-\mathrm{msec}$ ISI and up to $96 \%$ at the $250-\mathrm{msec}$ ISI. In other words, with this very stringent test of oddball detection (in which participants merely had to detect the presence of a color discontinuity with no further need to analyze the oddball item), we found that our masks had a significant impact on oddball detectability. We are therefore confident that our masks were indeed affecting the perceptual processing of the search items in Experiment 4B. Interestingly, even though speed was not stressed in this task, we analyzed the RT data and found no significant DPE in this experiment $[F(1,11)<1$, n.s.], which, once again, replicates our findings from Experiments 1 and 2, in which a DPE was not observed in the context of a detection task.

As a final point, it is worth reiterating that we tried to obtain effects of masking on the DPE in four independent groups of participants (one group in Experiment 4A, three in Experiment 4B), and we found that the salience of the previewed items did not alter the magnitude of the DPE, even though masking did affect the overall likeli- hood of detecting the presence of a color oddball (control experiment). Thus, we feel that the results of Experiments $4 \mathrm{~A}$ and $4 \mathrm{~B}$ do indeed suggest that the salience of the previewed items does not affect the overall magnitude of the DPE.

Taken together, the results from Experiments 1-4 strongly suggest that the DPE reflects an inhibitory trace that biases focused attention away from the failed feature viewed on target-absent trials. This bias stems from the fact that the failed feature prevented participants from successfully completing the discrimination task, which required focused attention. Furthermore, the results from our masking studies suggest that this effect can indeed emerge very quickly: When target-absent displays of $100 \mathrm{msec}$ were quickly followed by 600 -msec masking displays, a DPE was still observed. Next and last, we present Experiment 5 as a brief attempt to confirm this observation.

\section{EXPERIMENT 5}

The goal of Experiment 5 was to investigate how early in a trial the information leading to the DPE starts to influence performance. The strategy was to switch the colors of items at different points during the trial and then observe how the DPE was affected by the color switch. More specifically, during a target-present trial, the colors of all three items would change to the alternate color (only two colors were used for the search items). For example, if a target-present trial started as a display of one green and two red items, it would switch to a display of one red and two green items. Crucially, this switch preserved oddball status, so that the target item would remain the same before and after the switch (i.e., at the same location in the display). The color switch also preserved the missing side of the target diamond, so that the correct response for the trial would remain the same as well.

Regarding the DPE, it is clear that this color switch would reverse how the attentional bias created by the prior targetabsent trial affected focused attention in the current trial. If, for example, focused attention to red items had been inhibited, an initially green target should be easy to focus on, but if the green target turned red before participants had extracted shape information from it, focused attention to the target would be slowed down. On the other hand, one might argue that the DPE reflects inhibition not on attentional focusing, but on later information-processing stages, such as response selection or response execution. By manipulating the moment during the trial when the switch occurred, we sought to gather converging evidence that the DPE was indeed an early attentional phenomenon. If switches occurring early in the trial (within $100 \mathrm{msec}$ of display onset, for example) had an effect on the DPE, this would provide strong evidence that the DPE was indeed an effect arising early in the information-processing stream (as our attentional hypothesis would have it). If, however, the DPE was unaffected by the color of items early on in the trial, then this result would be more in line with a later locus of the phenomenon.

To anticipate, we found that the magnitude of the DPE was affected by a switch occurring as early as $100 \mathrm{msec}$ 
into the trial, corroborating our earlier findings on how quickly the DPE can emerge during a trial.

\section{Method}

Participants. Fifteen undergraduate students from the University of Illinois participated in this experiment in exchange for extra credit in an introductory psychology course or for $\$ 8$ for a 1-h session. All participants reported normal or corrected-to-normal visual acuity and normal color vision.

Apparatus, Task, and Stimuli. The apparatus, task, and stimuli used in Experiment 5 were identical to those used in Experiment 1 (target-discrimination condition), except that the stimuli simultaneously switched colors at one of four different points during the trial (see design section below). At switch time, all green items turned red and all red items turned green. Participants were directed to ignore this color switch and to complete the task as quickly as possible. During the practice block, experimenters emphasized to participants that target status and the target's response would not change during the switch.

Design. In target-present trials, the color of the items could switch at one of four different points: $0,100,250$, or $400 \mathrm{msec}$ after the beginning of the trial. In other words, the switch time represented the duration of the initial (preswitch) display. The DPE was calculated with respect to the preswitch color - thus, if participants had enough time to scrutinize the display before the switch, a positive DPE would be expected. Consequently, a negative DPE would reflect an effect based on the colors of the postswitch display. Importantly, in the 0 -msec switch time condition, no color switch actually took place: For internal consistency, items in that trial were coded as appearing immediately in the switched color (a 0-msec initial display duration). As a result, a negative DPE was expected on those trials.

Participants completed three blocks of 320 trials each, with additional breaks every 160 trials. In the 0 -msec switch time condition, there was a total of 96 trials for both the distractor- and the targetpreviewed trials. In the $100-\mathrm{msec}, 250-\mathrm{msec}$, and $400-\mathrm{msec}$ conditions, there was a total of 32 trials for both the distractor- and the target-previewed trials. In other words, on half of the target-present trials, no color switch actually occurred. In addition, $20 \%$ of trials were search trials that followed another search trial. This design did not allow for a careful examination of priming of pop-out dynamics, since in the 100-msec, $250-\mathrm{msec}$, and $400-\mathrm{msec}$ switch conditions, there were only 12 trials per search-repeat condition. However, this design was satisfactory for our purpose because we were most interested in the DPE dynamics.

\section{Results}

Because of the low number of observations in the priming of pop-out conditions, our analyses were confined to the DPE. First, we submitted accuracy data to an ANOVA with preview type (target previewed vs. distractor previewed) and switch time $(0,100,250$, and $400 \mathrm{msec})$ as within-subjects variables. Switch time had a significant effect on performance $[F(3,42)=5.74, p<.05]$, with the best accuracy $(95.3 \%)$ observed in the 0 -msec switch time condition (i.e., where no color switch actually occurred), followed by accuracy in the 100-msec switch condition (94.8\%), then accuracy in the 400-msec switch condition $(92.9 \%)$, with the worst performance in the $250-\mathrm{msec}$ switch condition (91.7\%). Preview type did not have a significant effect $[F(1,14)<1]$, nor did the preview type $\times$ switch time interaction $[F(3,42)<1]$.

Next, we analyzed RTs on correct trials in an analogous manner. All factors were significant. Switch time had a significant effect on performance, with the fastest RTs in the 0 -msec condition $(770 \mathrm{msec})$, followed by the RTs in the 100-msec and 400-msec conditions (849 and $848 \mathrm{msec}$, respectively), followed last by the RTs in the 250 -msec condition, which were the slowest $(890 \mathrm{msec})[F(3,42)=27.21$, $p<.05]$. Further, preview type was significant $[F(1,14)=$ $6.86, p<.05]$, but more crucially, the interaction of switch time $\times$ preview type was significant also $[F(3,42)=56.6$, $p<.05]$. Planned comparisons revealed that a DPE of $-78 \mathrm{msec}$ was observed in the 0 -msec condition $[t(14)=$ $-8.53, p<.05]$, and a DPE of $-31 \mathrm{msec}$ was also observed in the 100 -msec condition $[t(14)=-4.09, p<.05]$. In contrast, a DPE of $+55 \mathrm{msec}$ was observed in the $250-\mathrm{msec}$ condition $[t(14)=4.11, p<.05]$. Similarly, a $+108-\mathrm{msec}$ DPE was observed in the 400 -msec condition $[t(14)=$ 8.54, $p<.05]$. These data are summarized in Figure 5. Last, pairwise comparisons of DPE magnitudes confirmed that the DPE of -78 msec obtained in the 0 -msec switch condition was significantly larger in magnitude than the DPE of -31 msec obtained in the 100-msec switch condition $[t(14)=3.60, p<.05]$. Similarly, the $+108-\mathrm{msec}$ DPE obtained in the 400-msec switch condition was significantly larger than the +55 -msec DPE obtained in the 250 -msec switch condition $[t(14)=3.02, p<.05]$.

\section{Discussion}

The results of Experiment 5 show how early during a trial the DPE starts to emerge. Viewing a preswitch display for as few as $100 \mathrm{msec}$ significantly decreased the DPE created by the final display-from $78 \mathrm{msec}$ to $31 \mathrm{msec}$. In other words, the mechanisms responsible for the DPE affected performance from the earliest moments of a display's appearance. Furthermore, a tipping point seems to be reached somewhere between 100 and $250 \mathrm{msec}$, such that in the 100-msec switch condition, the DPE effect was mostly driven by the colors in the postswitch display, whereas in the later, 250-msec switch condition, the DPE

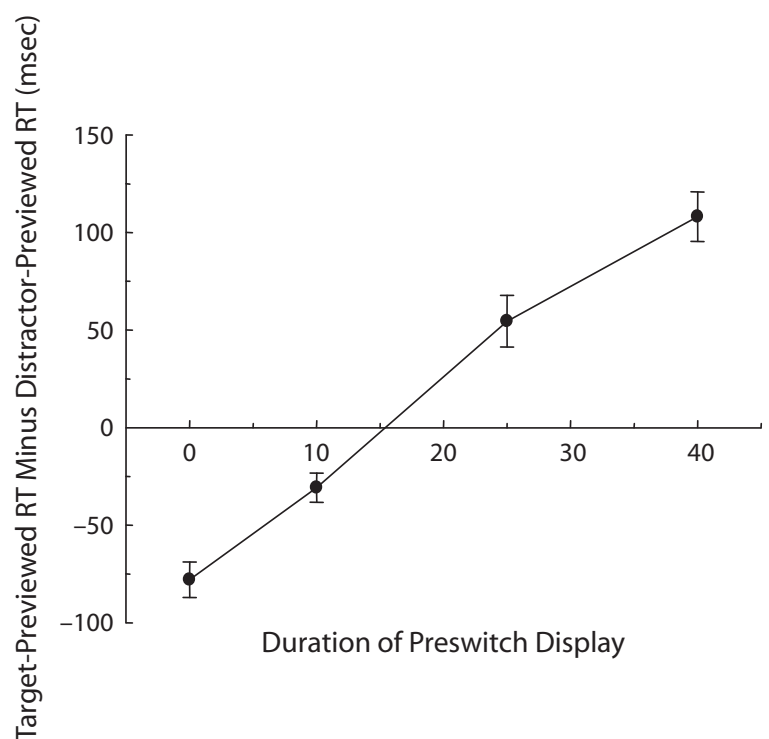

Figure 5. Difference between target-previewed response times (RTs) and distractor-previewed RTs in Experiment 5 as a function of the duration of the preswitch display. 
was mostly driven by the colors in the preswitch display. In other words, most of the work leading to the DPE had been completed before $250 \mathrm{msec}$ had elapsed. This is all the more remarkable when one considers that participants were actually viewing displays with opposite color assignments for most of the trial (from the time of the switch at $250 \mathrm{msec}$ to their response, which occurred around $850 \mathrm{msec}$ ). Last, the DPE seems to reach its maximum magnitude within the first $400 \mathrm{msec}$ of a trial, which is, again, relatively early in the trial given response latencies of around $850 \mathrm{msec}$. In sum, the results of Experiment 5 strongly suggest that the mechanisms responsible for the DPE are at play in the very early stages of a trial.

We take these data to be consistent with our hypothesis that the locus of the DPE is in the attentional system (as opposed to the response selection system or later systems). Because the participants in Experiment 5 viewed exactly the same pop-out displays that were used in Experiment 2, we can place the current data in the context of the results from that earlier experiment. In Experiment 2, participants completed a target-detection task and thus had to view a display, detect the presence or absence of a target, choose the appropriate response, and execute it. Overall RTs in Experiment 2 hovered around $400 \mathrm{msec}$. From those data, we can speculate that participants were most likely finding the target in the displays within the first $200 \mathrm{msec}$ of a trial, perhaps sooner (since we have to factor in response selection and execution after that point). Such estimates would be in line with the results of Experiment 5, since these estimates mean that participants would be able to start focusing on the target before the 250-msec mark, at least on a majority of trials. The fact that a DPE based on the initial (preswitch) display was obtained in the 250-msec switch time condition would suggest that participants did indeed start focusing on the target before the 250-msec mark in Experiment 5.

\section{GENERAL DISCUSSION}

The goal of this article was to understand the mechanisms underlying the DPE. A prior study proposed the DPE as a type of preattentive phenomenon, wherein the repeated experience of a color from a target-absent to a target-present display leads to the reduction of that color's salience on the second (target-present) display (see Goolsby et al., 2005). In contrast, we proposed that the DPE is an attentional phenomenon, wherein the failure to complete a search task on target-absent displays creates a bias in the attentional system not to focus on items that contain the target-absent feature. For example, if items in the target-absent trial are all red, red is deemed by the attentional system to be a failed feature ("failed" in that it did not allow for the completion of the task). As a result, focused attention becomes temporarily biased against focusing on red items. Thus, this bias can be understood as a type of inhibition on focused attention - that is, the ability to focus attention on the failed feature becomes inhibited.

To test the inhibitory account of focused attention, Experiments 1,2, and 3 compared performance by using the same displays but different tasks. The results consistently showed that when the experimental task required focused attention, a DPE was observed, whereas when the experimental task did not require focused attention, a DPE was not observed. This result was replicated even when the response characteristics of the various tasks were controlled for (Experiments 2 and 3). Crucially, the preattentive account of Goolsby et al. (2005) predicts that the presence of a DPE in all experiments - irrespective of task and, more specifically, irrespective of the attentional requirements of the tasks. This follows because merely perceiving the target-absent displays should be sufficient to modulate the salience of items in the subsequent target-present display. In sum, we believe that our results provide strong support for our inhibition of focused attention account. Interestingly, the results of Experiment 3 indicated that this intertrial inhibition created by target-absent displays affected RTs in two different ways. First, it yielded faster RTs to targets that were not of the color that had become inhibited than to targets that were of the inhibited color. Second, this intertrial inhibition also reduced the competition for attention from distractors that were of the inhibited color (thus producing faster RTs) compared with distractors that were not of the inhibited color (thus producing slower RTs).

To further test the color salience aftereffect account of the DPE without changing the experimental task, Experiment 4A compared performance on target-present trials that followed masked target-absent trials with performance on target-present trials that followed unmasked target-absent trials. The rationale for this manipulation was that mask displays, although totally irrelevant to the task at hand, should have reduced or interacted with the color aftereffect created by target-absent trials; however, no difference in performance was found between the masked and unmasked conditions. We took this result as further converging evidence that the locus of the DPE is likely not perceptual in nature. In other words, we believe that the results of Experiments 1-4 strongly suggest that the salience of items in target-present trials is likely not affected by the repetition/alternation of colors viewed during target-absent trials. Rather, our results suggest that the DPE is an attentional effect, whereby the mechanism of focused attention itself is biased against focusing on failed features.

Regarding the latter point, the results of Experiment 5 are eye-opening as well: The very early development of the DPE during a trial is consistent with an attentional locus of the phenomenon and speaks against later loci (such as response selection or response execution). One might argue that the DPE arises from conflicts in these later stages, but if it did, one would not expect modulations of the DPE within 100 msec of trial onset, when neither response selection nor response execution is likely to have started. These conclusions have now found support from an event-related potential (ERP) investigation on the DPE that we recently completed in our lab (Shin, Wan, Fabiani, Gratton, \& Lleras, in press). In that study, we measured well-known ERP components while participants completed a DPE task. The components of interest were: the P1/N1 complex (which can reveal differences in perceptual fluency between conditions; see Dehaene 
et al., 2001), the N2pc (which can reveal differences in attentional allocation; see Eimer, 1996; Luck \& Hillyard, 1994; Woodman \& Luck, 1999) and the LRPs (which can reveal differences in response selection and motor preparation; see Gratton, Coles, Sirevaag, Eriksen, \& Donchin, 1988). Consistent with our attentional account and with the results of Experiment 5, the N2pc was the only component that was modulated by the preview condition, with smaller N2pc in the target-previewed condition than in the distractor-previewed condition, as if attention allocation to the target had been suppressed in the target-previewedcondition trials.

\section{Salience Aftereffect or Inhibitory Attentional Trace?}

We began this study with the goal of testing whether focused attention played an important role in the DPE or whether this effect was entirely due to preattentive salience interactions stemming from the between-trial repetition of a given color. ${ }^{3}$ Goolsby et al. (2005) proposed that the DPE arose from the latter type of mechanisms, but it must be stated that these authors did not provide an explicit description of the mechanism whereby such salience aftereffects might come to be instantiated. Of critical importance to Goolsby and colleagues were the following two findings: (1) They did not observe a DPE when the previewed color was presented as a colored blob in the middle of the screen (instead of being previewed as the color of items in a search array), and (2) they observed a DPE even when they asked participants to focus their attention on a single item in the preview display (with the goal of completing a second task). On the basis of the first finding, Goolsby et al. concluded that the effect must have arisen at a late stage of processing in which color and shape attributes would have been bound into object representations (perhaps in the inferotemporal [IT] cortex), since simply viewing a color did not seem to produce a salience aftereffect for that color. However, this claim was mostly speculative in that the authors did not test for the involvement of IT cells in the DPE. On the basis of the second finding, Goolsby et al. concluded that the effect must have arisen prior to the deployment of focused attention, since they found only a slight (not significant) reduction in the magnitude of the DPE when participants were asked to focus attention on the preview display, compared with when they were asked not to do so.

In contrast with Goolsby et al. (2005), we took a different approach to studying the DPE. Rather than testing which preview displays gave rise to a DPE, we tested which tasks did. This is a powerful test for any salience account of the DPE since it ensures that participants always view exactly the same displays but have to compute different things from them, depending on the experimental task. What our experiments consistently showed was that a task that did not require focused attention did not produce a DPE, whereas a task that involved focused attention did produce a DPE. As a first conclusion, we can safely say that the attentional requirements of the task play a crucial role in the development of the DPE. But how strong an argument against the salience aftereffect is this? Two key points need to be mentioned. Salience differences, when present, affect both detection and discrimination tasks, as has been demonstrated empirically (Wan \& Lleras, 2007), theoretically (Wolfe, 1994), and computationally (Navalpakkam \& Itti, 2007). So, if the same displays were used in both a discrimination task and a detection task, and a salience difference was present in the former, then it should have been present in the latter as well. In the present study, we showed that this was not the case. Second, our electrophysiological recordings showed no hint of early, preattentive differentiation of target-previewed versus distractorpreviewed trials, yet a strong effect was observed on the $\mathrm{N} 2 \mathrm{pc}$ component, which has traditionally been interpreted as an index of attentional allocation. Consistent with our attentional account, the N2pc emerged more slowly and peaked lower in the target-previewed condition than in the distractor-previewed condition.

In sum, our evidence suggests a strong involvement of attention in the DPE, yet Goolsby et al. (2005) found that a DPE was present even when participants focused attention on the previewed display, suggesting that focusing attention on the preview display does not eliminate the DPE. We believe that Goolsby et al. observed a DPE even when participants were asked to focus attention on one item in the target-absent display because participants still had to abort a search of those displays. Put differently, we believe that participants develop an automatic tendency to search through these task-relevant displays, and they do so even in the presence of a secondary task (as was the case in Experiments 3.3A and 3.3B of Goolsby et al., 2005) or when they know in advance that the next trial will not contain a target and that they could therefore theoretically refrain from searching (as in Experiment 3.2 of Goolsby et al., 2005; see also Ariga et al., 2004). It is also worth pointing out that when displays do not afford searching (i.e., when they do not look like search displays), the DPE is absent. This was the case in the color blob experiment of Goolsby et al. (Experiment 2.1), as well as in their Experiment 2.2, in which target-absent displays were made to look like a face.

A second goal of this article was to directly test whether we could modulate the DPE by changing the salience of the previewed items and thus provide a different way of testing the color salience aftereffect account. However, directly manipulating the salience of the target-absent displays failed to produce differences in the DPE. Evidence for this comes from three sources: (1) Experiment 4B, in which no difference in the magnitude of the DPE was observed between masked and unmasked trials in the context of a discrimination task; (2) the control experiment, in which no DPE was observed for various levels of oddball discriminability in the context of a detection task; and (3) a color salience manipulation (without masks), which we have reported elsewhere (Wan \& Lleras, 2007), in which the target-distractor color similarity was manipulated (high or low), but the magnitude of the DPE was identical across both conditions, even though the manipulations created large differences in overall RTs.

As a result, it appears that an exclusively preattentive salience account of the DPE is insufficient to account for 
the extant data and that attention is indeed intimately involved in producing this effect. But does this mean that salience plays no role whatsoever in this effect? It is difficult to say. It is possible that the inhibitory trace that we believe is created at the end of a target-absent trial might actually be instantiated at the level of feature maps. In other words, it is possible that (1) an inhibitory trace is created only in the context of failed searches (which may occur only in tasks requiring focused attention) and that (2) that trace may be instantiated as an overall decrease in the activation of the associated feature map (such as a lowering of all outputs from a red feature map following a red target-absent display). If so, such an effect would be present only in tasks requiring attention, and it could be additive with other salience manipulations, if one follows, for example, Wolfe's (1994) guided search model of visual search, which posits that all salience calculations are additive in nature. The result would also be a relative bias against attending to red targets insofar as the overall salience of red items would be relatively reduced with respect to the salience of, say, green items.

In sum, we can confidently conclude two things: (1) The DPE is not solely based on preattentive salience aftereffect interactions, and (2) the DPE is an attentional phenomenon, insofar as it is present in tasks that require focused attention and absent in tasks that do not require focused attention. We view the effect as a bias to focus attention away from failed features, but we grant that this effect might actually be instantiated in feature or salience maps, as proposed in traditional models of visual search (Treisman \& Gelade, 1980; Wolfe, 1994) and also in recent work on salience maps involved in oculomotor control (Fecteau \& Munoz, 2003, 2006). In the latter, Fecteau and Munoz proposed that attentional selection occurs on the basis of a salience-based representation that incorporates trial history and task relevance into its computation (Fecteau, 2007).

\section{Feature-Based Inhibition of Return?}

Last, we believe that our understanding of the DPE reflects mechanisms analogous to those proposed in current models of IOR (Klein, 2000; Klein \& MacInnes, 1999; MacInnes \& Klein, 2003; Posner \& Cohen, 1984), albeit in a featural domain rather than a spatial one. Current models of IOR describe it as a bias not to focus attention on failed locations or failed objects. In this context, failed locations are understood as locations that do not contain the target, and failed objects as objects that are not the target. In IOR, the conclusion that a location or object is a failed one is reached when attention focuses on the location or the object and fails to find the target - in other words, when the examination of a location or an object does not allow for the successful completion of the task. Note that when IOR is studied in the context of an orienting task (as in the original study by Posner \& Cohen, 1984), IOR arises after an early phase of facilitation is observed at the cued location. In other words, attention is allocated to the cued location, and initially, this allocation leads to a behavioral benefit when the target appears at that location. However, if the target fails to appear within a few hundred milliseconds, attention is withdrawn from that location and IOR ensues, resulting in longer processing times if the target does appear at that location later on. It seems as if the attentional allocation at that location had been aborted due to the failure of the target to appear there.

In this manner, we see IOR and DPE as analogous attentional mechanisms. In IOR, inspection of failed locations and failed objects is aborted in an attempt to optimize performance in the near future. When inspection ends, something akin to an inhibitory tag is associated with the inspected location or object. Similarly, we see the DPE as an inhibitory tag associated with the failed color viewed during a target-absent trial. This failed tag can be seen as an adaptive strategy, similar to IOR, that biases attention away from colors that have recently failed to contain a target. In sum, both phenomena seem to represent a systematic bias not to focus attention on failed features in the display-locations or objects in the context of IOR, visual features in the context of the DPE. We are currently investigating the similarities between these two effects.

\section{Visual Marking and the DPE}

One final note is worthy of attention. Readers familiar with the visual marking effect (Watson \& Humphreys, 1997) might have detected important similarities between that effect and the DPE. In a typical visual marking experiment, participants are asked to find the single blue $\mathrm{H}$ in a field of blue As and green Hs. This is a demanding task and typically produces a nonzero search slope. The crucial condition in visual marking comes when participants are given a preview of one subset of distractors - a 1-sec view of the green Hs, for example. Later, on the trial, the second set of items appears, comprising blue items (several As and the target H). On these preview trials, the participants' searches are much more efficient - as efficient, in fact, as if participants had only looked through the second set of blue items. The name "visual marking" refers to the interpretation that participants searched through the display as if they had visually marked the first set of initial distractors and then stayed away from those distractors when the second set of items was presented.

The literature on visual marking is very rich and has produced important debates about marking's underlying mechanisms; nonetheless, at least on the surface, visual marking bears great resemblance to the DPE. In both cases, participants first view a set of items that does not contain the target, then view a set of items of a different color that does contain the target. A second similarity is the behavioral benefit obtained from previewing items that do not share the target color shortly before a set of items of a different color that does contain the target appears. However, there are more differences than similarities between these two effects. First, in visual marking, even in conditions of perfect marking (when all distractors seem to be ignored), the search often remains inefficient, with search slopes larger than zero, whereas the DPE is observed solely in pop-out searches that have zero slope (see Wan \& Lleras, 2007). In other words, whereas visual marking seems to be a search effect (i.e., a modulation 
of the speed at which the target is found within a set of distractors), the DPE seems to be a selection effect (i.e., a modulation of the speed at which attention focuses on the pop-out item), insofar as detecting the target occurs in parallel (Wan \& Lleras, 2007, Experiments 1 and 2).

A second important difference pertains to the informational value of the preview display. In the DPE, the preview display carries no information regarding the color of the target in the subsequent display (i.e., the previewed color does not predict the color of the target), whereas the preview color is perfectly predictive of the target color in the visual marking paradigm: Previewing green items informs the system that the target will be blue, and therefore the kind of bias created in visual marking might be different from the one observed in the DPE. Third, whereas in visual marking the previewed items remain on the screen when the set of items containing the target appears (thus allowing for the creation of location tags to mark the location of old items; see Watson \& Humphreys, 1997), the previewed items that give rise to the DPE are long gone when the target set appears. As a result, location-based tagging of old items is impossible in the context of the DPE, whereas such tagging could be a mechanism through which visual marking is instantiated.

The predominant alternative account of visual marking relies not on location tagging of old items, but rather on prioritization of the new items via bottom-up processesprobably as a result of attentional capture by the new set of onsets (Donk \& Theeuwes, 2001, 2003). This account is also mute with respect to the DPE since, once again, in the context of the DPE, all items in the target-present display appear simultaneously, long after the target-absent items have disappeared. In sum, in spite of a surface similarity between the DPE and the visual marking effect, some important methodological and theoretical differences between the two exist. That being said, our lab is actively investigating whether any DPE-type influences can be observed in a visual marking paradigm (Chu, Levinthal, \& Lleras, 2007), and this will remain an active research effort in our lab.

\section{Conclusion}

In conclusion, we believe that our data present strong evidence against a preattentive, color salience aftereffect type of account of the DPE, while consistently providing evidence in favor of a privileged role for attention in the phenomenon. In our view, the DPE is an attentional effect that signals a bias against focusing attention on features that have recently led to failed trials - that is, trials that did not lead to the successful completion of the target task (here, a shape discrimination). In this way, we believe that the DPE is analogous to IOR, which biases attention away from failed locations or objects.

\section{AUTHOR NOTE}

This work was partially supported by Grants 0527361 and 0309998 from the National Science Foundation to A.L. and by Grant 17730433 from the Japan Society for the Promotion of Science to J.-I.K. We thank Jeremy Wolfe for valuable discussions about the possible instantiations of this effect within a computational model of search, and we thank our reviewers for their thoughtful comments on a previous version of this manuscript. Correspondence concerning this article should be addressed to A. Lleras, Department of Psychology and Beckman Institute, University of Illinois at Urbana-Champaign, 603 E. Daniel St., Champaign, IL 61820 (e-mail: alleras@uiuc.edu).

\section{REFERENCES}

Ariga, A., \& KaWahara, J. (2004). The perceptual and cognitive distractor-previewing effect. Journal of Vision, 4, 891-903.

Ariga, A., Lleras, A., \& Kawahara, J. (2004). Task relevance and response suppression in the distractor previewing effect [Abstract]. Journal of Vision, 4, 687a.

Brainard, D. H. (1997). The Psychophysics Toolbox. Spatial Vision, 10, 433-436.

Bravo, M. J., \& NAKAYAMA, K. (1992). The role of attention in different visual-search tasks. Perception \& Psychophysics, 51, 465-472.

Breitmeyer, B. G., Ogmen, H., \& Chen, J. (2004). Unconscious priming by color and form: Different processes and levels. Consciousness \& Cognition, 13, 138-157.

Breitmeyer, B. G., Ro, T., \& Singhal, N. S. (2004). Unconscious color priming occurs at stimulus- not percept-dependent levels of processing. Psychological Science, 15, 198-202.

Chu, H., Levinthal, B., \& Lleras, A. (2007, May). What is being marked in visual marking? Poster presented at the annual meeting of the Vision Sciences Society, Sarasota, FL.

Dehaene, S., Naccache, L., Cohen, L., Le Bihan, D., Mangin, J.-F., Poline, J.-B., \& Rivière, D. (2001). Cerebral mechanisms of word masking and unconscious repetition priming. Nature Neuroscience, 4, $752-758$.

Donk, M., \& Theeuwes, J. (2001). Visual marking beside the mark: Prioritizing selection by abrupt onsets. Perception \& Psychophysics, 63, 891-900.

Donk, M., \& Theeuwes, J. (2003). Prioritizing selection of new elements: Bottom-up versus top-down control. Perception \& Psychophysics, 65, 1231-1242.

DownING, P. E. (2000). Interactions between visual working memory and selective attention. Psychological Science, 11, 467-473.

EIMER, M. (1996). The N2pc component as an indicator of attentional selectivity. Electroencephalography \& Clinical Neurophysiology, 99, 225-234.

Fecteau, J. H. (2007). Priming of pop-out depends upon the current goals of observers. Journal of Vision, 7, 1-11.

Fecteau, J. H., \& MunOz, D. P. (2003). Exploring the consequences of the previous trial. Nature Reviews Neuroscience, 4, 435-443.

Fecteau, J. H., \& Munoz, D. P. (2006). Salience, relevance, and firing: A priority map for target selection. Trends in Cognitive Sciences, 10, 382-390.

Folk, C. L., Leber, A. B., \& Egeth, H. E. (2002). Made you blink! Contingent attentional capture produces a spatial blink. Perception \& Psychophysics, 64, 741-753.

Goolsby, B. A., Grabowecky, M., \& SuZuki, S. (2005). Adaptive modulation of color salience contingent upon global form coding and task relevance. Vision Research, 45, 901-930.

Goolsby, B. A., \& SuZuKI, S. (2001a, November). Color priming and adaptation in color-singleton search. Paper presented at the annual Object Perception, Attention, and Memory conference, Orlando, FL.

GoolsBY, B. A., \& SUZUKI, S. (2001b). Understanding priming of colorsingleton search: Roles of attention at encoding and "retrieval." Perception \& Psychophysics, 63, 929-944.

Gratton, G., Coles, M. G. H., Sirevaag, E. J., Eriksen, C. W., \& Donchin, E. (1988). Pre- and poststimulus activation of response channels: A psychophysiological analysis. Journal of Experimental Psychology: Human Perception \& Performance, 14, 331-344.

IтTі, L., \& Косн, C. (2000). A saliency-based search mechanism for overt and covert shifts of visual attention. Vision Research, 40, 1489-1506.

KLEIN, R. M. (2000). Inhibition of return. Trends in Cognitive Sciences, 4, 138-146.

KLEIN, R. M., \& MacInNES, W. J. (1999). Inhibition of return is a foraging facilitator in visual search. Psychological Science, 10, 346-352.

LABERge, D., \& Brown, V. (1989). Theory of attentional operations in shape identification. Psychological Review, 96, 101-124.

LowE, D. G. (1979). Strategies, context, and the mechanism of response inhibition. Memory \& Cognition, 7, 382-389. 
Lu, J., \& ITTI, L. (2005). Perceptual consequences of feature-based attention. Journal of Vision, 5, 622-631.

LuCK, S. J., \& Hillyard, S. A. (1994). Spatial filtering during visual search: Evidence from human electrophysiology. Journal of Experimental Psychology: Human Perception \& Performance, 20, 1000-1014.

Macinnes, W. J., \& Klein, R. M. (2003). Inhibition of return biases orienting during the search of complex scenes. Scientific World Journal, 3, 75-86.

Maljkovic, V., \& Nakayama, K. (1994). Priming of pop-out: I. Role of features. Memory \& Cognition, 22, 657-672.

Maljkovic, V., \& Nakayama, K. (1996). Priming of pop-out: II. The role of position. Perception \& Psychophysics, 58, 977-991.

Maljkovic, V., \& Nakayama, K. (2000). Priming of popout: III. A short-term implicit memory system beneficial for rapid target selection. Visual Cognition, 7, 571-595.

McCarley, J. S., Wang, R. F., Kramer, A. F., Irwin, D. E., \& Peterson, M. S. (2003). How much memory does oculomotor search have? Psychological Science, 14, 422-426.

Milliken, B., Joordens, S., Merikle, P. M., \& Seiffert, A. E. (1998). Selective attention: A reevaluation of the implications of negative priming. Psychological Review, 105, 203-229.

Moore, C. M. (1994). Negative priming depends on probe-trial conflict: Where has all the inhibition gone? Perception \& Psychophysics, 56, 133-147.

NavalPaKKam, V., \& ItTi, L. (2007). Search goal tunes visual features optimally. Neuron, 53, 605-617.

PelLi, D. G. (1997). The VideoToolbox software for visual psychophysics: Transforming numbers into movies. Spatial Vision, 10, 437-442.

Peterson, M. S., Kramer, A. F., Wang, R. F., Irwin, D. E., \& McCarLEY, J. S. (2001). Visual search has memory. Psychological Science, 12, 287-292.

Posner, M. I., \& Cohen, Y. A. (1984). Components of visual orienting. In H. Bouma \& D. G. Bouwhuis (Eds.), Attention and performance X: Control of language processes (pp. 531-554). Hillsdale, NJ: Erlbaum.

Rovamo, J., \& Virsu, V. (1979). Visual resolution, contrast sensitivity, and the cortical magnification factor. Experimental Brain Research, 37, 475-494.

Saenz, M., Buracas, G. T., \& Boynton, G. M. (2003). Global featurebased attention for motion and color. Vision Research, 43, 629-637.

Shin, E., Wan, X. I., Fabiani, M., Gratton, G., \& Lleras, A. (in press). Electrophysiological evidence of feature-based inhibition of focused attention across consecutive trials. Psychophysiology.

Thomas, L. E., Ambinder, M. S., Hsieh, B., Levinthal, B., Crowell, J. A., Irwin, D. E., ET AL. (2006). Fruitful visual search: Inhibition of return in a virtual foraging task. Psychonomic Bulletin \& Review, 13, 891-895.

TIPPER, S. P. (1985). The negative priming effect: Inhibitory priming by ignored objects. Quarterly Journal of Experimental Psychology, 37A, 571-590.

TipPeR, S. P., \& CRANSTON, M. (1985). Selective attention and priming: Inhibitory and facilitatory effects of ignored primes. Quarterly Journal of Experimental Psychology, 37A, 591-611.
Treisman, A. M., \& Gelade, G. (1980). A feature-integration theory of attention. Cognitive Psychology, 12, 97-136

Treisman, A. [M.], \& Souther, J. (1985). Search asymmetry: A diagnostic for preattentive processing of separable features. Journal of Experimental Psychology: General, 114, 285-310.

WAN, X. I., \& LLERAS, A. (2007). The effect of feature discriminability on the inter-trial inhibition of focused attention. Manuscript submitted for publication.

Watanabe, T., Harner, A. M., Miyauchi, S., Sasaki, Y., Nielsen, M., Palomo, D., \& MukaI, I. (1998). Task-dependent influences of attention on the activation of human primary visual cortex. Proceedings of the National Academy of Sciences, 95, 11489-11492.

Watson, D. G., \& Humphreys, G. W. (1997). Visual marking: Prioritizing selection for new objects by top-down attention inhibition of old objects. Psychological Review, 104, 90-122.

WoLfe, J. M. (1994). Guided Search 2.0: A revised model of visual search. Psychonomic Bulletin \& Review, 1, 202-238.

Wolfe, J. M., CAVE, K. R., \& Franzel, S. L. (1989). Guided search: An alternative to the feature integration model for visual search. Journal of Experimental Psychology: Human Perception \& Performance, $\mathbf{1 5}$ 419-433.

Woodman, G. F., \& LucK, S. J. (1999). Electrophysiological measurement of rapid shifts of attention during visual search. Nature, $\mathbf{4 0 0}$, $867-869$

\section{NOTES}

1. "This color salience aftereffect was broadly tuned to color and generally insensitive to cognitive factors such as expectancy, attention and behavioral response." (Goolsby et al., 2005, p. 927)

2. This intermediate RT observed in the neither-previewed condition also helps us to rule out another possible account of the DPE. One might argue that the DPE arises from the fact that more updating of the scene is required on target-previewed trials than on distractor-previewed trials, since in the former case, two items change color, whereas in the latter, only one item (the target) changes color. As a result, one might argue that the DPE arises from the greater updating of scene properties on targetpreviewed trials. However, the condition that requires the most scene updating is the neither-previewed condition, which yielded an intermediate RT (as predicted by the attentional account) and thus clearly contradicts the scene-updating account. We thank an anonymous reviewer for pointing out this interesting aspect of our results.

3. The discussion that follows centers on the DPE as a color-based effect. However, it should also be noted that we have observed an analogous effect with pop-out searches for shape (Wan \& Lleras, 2007) and that Ariga and Kawahara (2004) found analogous effects with more complex stimuli, such as moving dots and faces. A more thorough investigation of the similarities and differences between these effects remains to be performed.

(Manuscript received August 4, 2006 revision accepted for publication July 10, 2007.) 